(

\title{
INVESTMENT COMPANY INSTITUTE
}

PALL SCHOTT STEVENS

PRESIDENT

September 2, 2004

Mr. Paul F. Roye

Director

Division of Investment Management

U.S. Securities \& Exchange Commission

901 E Street, NW, Room 7086

Washington, DC 20549

Dear Paul:

I enclose for your information a copy of a study commissioned by the Institute concerning remedies to the problem of market timing. The study is entitled On Solutions to the Mutual Fund Timing Problem, and was authored by Gregory Bryant Kadlec, Pamplin Professor of Finance at Virginia Polytechnic Institute.

Drawing upon published research, Professor Kadlec concludes that fair valuation and other trading frictions (such as redernption fees or trading restrictions) are necessary to stop market timing in mutual furnds. Fle notes that market timing stems from the predictability of net asset values, and that this predictability can arise from the use of stale prices to value securities and from other sources that are inherent in the detennination of securities prices. In line with SEC guidelines, fair valuation of portfolio securities orly involves the removal of staleness; it does not, ard should not, eliminate other sources of predictability. In the absence of trading frictions, as Professor Kadlec observes, market timers and arbitrageurs can exploit the predictability in ret asset values that persists even after fair valuation.

In light of the Commission's ongoing consideration of proposed rules designed to curb the potential for market timing of fund shares, we believe the Kadlec study is especially timely and will be of particular interest to you.

Should you have any questions about the study, please do not hesitate to contact Professor Kadlec at (540) 231-4316, or John Rea, Chief Econornist of the Institute, at (202) 326-5910.

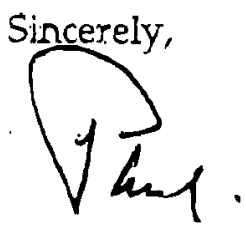

Enclosure 


\section{RECEIVED \\ FEB 172005 \\ OFFICE OF THE SECRETARY}

\section{On Solutions to the Mutual Fund Timing Problem}

$$
57-11-04
$$

Gregory Bryant Kadlec

Pamplin Professor of Finance

Virginia Polytechnic Institute 


\section{On Solutions to the Mutual Fund Timing Problem}

\section{Executive Summary}

The fact that individuals can time their purchase and redemption of mutual fund shares to expropriate wealth from other fund holders is well documented. ${ }^{1}$ The appropriate solution to the mutual fund timing problem remains the subject of much debate. Some argue that fair value pricing is the end-all be-all solution while others argue that redemption fees are the answer. This article provides an overview of the key economic issues and considers the relative merits of alternative solutions to the mutual fund timing problem. In principle, the timing problem could be fully resolved by either removing predictability from NAVs (i.e., fair value pricing) or imposing barriers to its exploitation (i.e., redemption fees). Because of the practical limitations of removing predictability and the cost of imposing barriers, the most effective and efficient solution involves a balanced and modest attack on each front.

\section{The Source of the Mutual Fund Timing Problem}

In order to evaluate potential solutions, it is imperative that we understand the root cause of the mutual fund timing problem. Two factors contribute to fund timing opportunities: (1) mutual fund prices (NAVs) are predictable, and (2) in the absence of transaction costs or other transaction frictions, that predictability is exploitable. This section provides a brief overview of these factors.

\section{A. Mutual Fund NAVs are Predictable}

Mutual fund NAVs are predictable because: (1) the prices of the underlying securities in the fund's portfolio are predictable - even when they have recently traded, and (2) mutual funds introduce additional predictability when they use stale prices of securities that have not recently traded to compute NAV.

\section{Predictability in Underlying Security Returns}

Scores of studies, dating back to Cowles and Jones (1937), document predictability in short-horizon security returns. For example researchers have identified: a weekend effect, a January effect, a post-earnings announcement drift, lead-lag relations, and autocorrelation among other patterns. ${ }^{2}$ In his survey on the efficiency of capital markets

\footnotetext{
${ }^{1}$ For studies of mutual fund timing see i.e., Bhargava, Bose and Dubofsky (1998), Chalmers, Edelen and Kadlec (2001), Goetzmann, Ivkovic, and Rouwenhorst (2001), Greene and Hodges (2002), Boudoukh, Richardson, Subrahmanyam, and Whitelaw (2002), and Zitzewitz (2003).

${ }^{2}$ For studies of short-horizon security return predictability see i.e., French (1980), Gibbons and Hess (1981), Rozeff and Kinney (1976), Reinganum (1981), Jegadeesh and Titman (1993), Foster, Olsen, Shevlin (1984), Bernard and Thomas (1990)], Conrad and Kaul (1988), Badrinath, Noe, and Kale (1995), Hawawini (1980), and Lo and MacKinlay (1990).
} 
Fama (1991) concludes that: "recent research is able to show confidently that daily and weekly returns are predictable from past returns". The fact of the matter is, even when a security has recently traded its price may not fully reflect all available information -- it takes time for markets to fully assimilate information. ${ }^{3}$ It is important to note that, many of the predictive relations in security returns identified by researchers have nothing to do with market return volatility (i.e., weekend effect, January effect), and thus, the potential exploitation of predictability in mutual fund NAV is not confined to so called market timing strategies. This in fact, is one of the reasons why I use the more general term "fund" timing as opposed to "market" timing to characterize this problem. ${ }^{4}$

\section{Artificial Predictability due to Stale Prices}

Given the fact that security prices are predictable and mutual funds are portfolios of securities, it should come as little surprise that mutual fund prices are predictable. However, the predictability in mutual fund prices differs from that of its underlying securities in two important ways. First, mutual funds add substantially to the true predictability of the underlying securities in their portfolio when they use stale security prices to compute their $\mathrm{NAV} .^{5}$ A security's price is said to be stale when value relevant information has arrived since the time the security last traded. Because the security's last trade price does not reflect this information, one can predict changes in value computed from stale prices using, for example, the return on a relevant market index since the time of last trade. Kadlec and Patterson (1999) show that staleness accounts for roughly $50 \%$ of market return predictability in daily returns of portfolios of domestic equities. Given the fact that last trade prices of foreign assets are considerably more stale at the time the NAV is set, it is likely to account for substantially more of the predictability in foreign versus domestic fund NAVs. A preliminary analysis of American Depository Receipts suggests that staleness accounts for roughly $75 \%$ of market return predictability in daily returns of foreign equities.

Academics have long regarded predictability due to stale prices as an illusion because attempts to exploit it in our capital markets are sure to be met with the realization that market participants will typically not transact at the last trade price if relevant information has arrived since the last transaction. However, the illusion becomes a reality in the context of mutual funds that set the price at which investors purchase and redeem fund shares using last trade prices.

\footnotetext{
${ }^{3}$ The finance literature has identified a number of factors that may contribute to price-adjustment delays. See i.e., Goldman and Sosin (1979), Hasbrouck and Sofianos (1993), Kavajecz and Odders-White (2003), Adamati and Pfleiderer (1988), Bessembinder and Hertzel (1993), Brennan, Jagadeesh, Swaminathan (1993), and Barberis and Thaler (2003).

${ }^{4}$ The "market timing" label is also misguided in that: the exploitation of predictability in fund NAV is not the result of one's ability to time the market, but rather the ability to time the fund pricing mechanism, whose vulnerability is related to market volatility in some, but not all cases.

${ }^{5}$ Studies dating back to Fisher (1966) examine this (stale prices) artificial source of predictability in portfolio returns. See i.e., Lo and MacKinlay (1990), Boudoukh, Richardson and Whitelaw (1994), and Kadlec and Patterson (1999).
} 


\section{B. In the Absence of Transaction Costs, Predictability is Exploitable}

A second factor that contributes to fund timing opportunities is that the profit opportunities that arise from predictable NAVs are often greater than mutual funds' transaction fees. As mentioned above, researchers have uncovered a number of predictive relations in security returns. The primary reason why this predictability is not arbitraged away in our capital markets is because the cost of transacting typically exceeds the profit opportunity. However, in the context of mutual funds that charge little or no transaction fees, even the smallest amount of predictability can be exploited. Thus, an unfortunate consequence of providing fund holders with a high degree of liquidity is that they can be exposed to potential exploitation by arbitrageurs.

\section{Solutions to the Fund Timing Problem}

As noted above, mutual fund timing opportunities arise because: (1) mutual fund NAVs are predictable and (2), in the absence of transaction costs or other transaction frictions, that predictability is exploitable. Thus, fund timing opportunities can be eliminated by removing predictability from NAV, imposing barriers to its exploitation, or some combination of the two. This section considers the relative merits of alternative solutions to the fund timing problem.

\section{A. Removing Predictability in NAV}

The most direct solution to the fund timing problem is to remove predictability in NAVs. We will consider two approaches that address this predictability.

\section{Fair value pricing}

The objective of fair value pricing, as defined by the SEC, is to adjust the prices of the fund's underlying securities for staleness - not to remove all predictability in the prices of the underlying securities. ${ }^{6}$ Indeed, in their December 1999 letter to the ICI, the SEC states: "Ascertaining fair value requires a determination of the amount that an armslength buyer, under the circumstances, would currently pay for the security. Fair value cannot be based on what a buyer might pay at some later time." Correcting staleness involves estimating current prices whereas removing all predictability involves forecasting future prices. ${ }^{7}$

\footnotetext{
${ }^{6}$ Not everyone shares this interpretation. At least one pricing vendor asserts that the objective of fair value pricing is to remove all short-horizon return predictability.

${ }^{7}$ I believe that correcting staleness is a more reasonable objective than removing all predictability for several reasons. First, procedures for correcting staleness are based on simple well-accepted theoretical models (market model, portfolio theory). By contrast procedures for removing all predictability are necessarily more complex and largely ad hoc, given our lack of understanding of security return predictability. Second, procedures for correcting staleness do not presume to know more about value than the market itself - if a recent transaction price is available it is the sole basis for valuation. By contrast procedures for removing all predictability second-guess market determined prices even in those cases where the security has recently traded.
} 
The virtue of fair value pricing is that, in principle, it eliminates one source of fund timers' profits without imposing substantial costs (redemption fees) on fund investors. There are, however, important practical limitations to fair value pricing. First, fair value pricing, as currently defined, will not remove all predictability in NAV, because stale security prices are not the only source of predictability in NAV. Even if the objective of fair value pricing were to remove all predictability, it is virtually certain that no fair value pricing methodology can remove it all. Security return predictability is too complex and dynamic to be captured by a model.$^{8}$ Indeed, researchers still debate whether some of the apparent sources of predictability are spurious or real and it is inevitable that there are many other sources of predictability yet to be documented.

Moreover, regardless of the objective, all fair value pricing methodologies will introduce their own artificial source of predictability in NAV. Lacking a perfect fair value model, there will be times when the pricing vendor adjusts too little and times when the vendor adjusts too much. When the vendor adjusts too much they have introduced predictability that was not there before. To the extent that some arbitrageurs know more about the true relation between available information and fair value than the pricing vendor, they will exploit it.

All of this is not to suggest that fair value pricing does more harm than good - even simple fair value pricing models that correct only for staleness will eliminate $50-75 \%$ of fund timers' profit opportunities. However, fair value pricing, no matter how sophisticated the model, is not an end-all be-all solution. The NAV from any fair value pricing model will always be predictable to some degree. And, in the absence of transaction costs or other transaction frictions, that predictability will be exploitable.

\section{Next-day fund pricing}

An alternative to directly removing predictability in mutual fund NAV is to effectively remove it, through next-day pricing of fund shares. With next-day pricing, an individual who wishes to purchase or redeem fund shares today does so at tomorrow's NAV. By placing a 1-day gap between the time at which the investors' decision to transact in fund shares is made and the time at which those transactions are priced, next-day pricing eliminates the usefulness of individuals' ability to predict next-day fund prices. Given the fact that predictability in fund NAV is greatly attenuated after 1 day, this would substantially reduce the profitability of fund timing trades. In addition to reducing profitability, it would also subject fund timers to an additional day of risk, and thus, further reduce the Sharpe ratio of their timing strategies. The virtues of this approach are its simplicity (it does not require a fair value pricing model) and its low explicit cost. Its drawbacks are: (1) the cost of implementation (the magnitude of which I cannot gauge),

\footnotetext{
${ }^{8}$ Zitzewitz (2003) reports that current fair value pricing models are capable of removing $95 \%$ of NAV predictability. However, his tests presume that NAV predictability is confined to a simple linear relation between next-day fund returns and current day market returns. They fail to recognize more complex (nonlinear) relations between next-day fund returns and current-day market return as well as other forms of predictability such as the weekend effect, January effect, etc - that arbitrageurs are likely to use. Thus, it is likely that his evidence greatly overstates the ability of fair value models in removing NAV predictability.
} 
(2) the fact that, as in the case of fair value pricing, it is incomplete -- there would still be some potential for exploitation, and (3) it undermines the provision of liquidity by mutual funds. The loss of liquidity, is perhaps its greatest limitation, with next-day pricing subjecting all individuals to an additional 24 hour delay in transacting. Delays of such magnitude could be very disconcerting to investors during periods of high market volatility.

\section{B. Trading Friction Solutions}

An alternative to removing predictability in NAV is to impose barriers that preclude its exploitation. We will consider two such approaches.

\section{Redemption Fees}

Predictability is typically not exploitable in capital markets because transaction costs more than offset the potential profits from trading strategies devised to capture the predictability. By contrast, in the context of mutual funds that charge no redemption fee, even the smallest amount of predictability is exploitable. The virtue of redemption fees is that, if sufficiently large, they more than offset potential gains from fund timing. There are, however, several drawbacks. First, redemption fees undermine one of the benefits of investing in mutual funds - liquidity. Second, redemption fees are only effective to the extent that they are applied to all investors in the fund. There may be practical limitations in that some retirement plan contracts prohibit redemption fees, and there are complications in imposing redemption fees on omnibus accounts. Nevertheless, if they are of sufficient magnitude and duration and implemented uniformly, redemption fees are probably the single most effective way to stop fund timing - though costly. For example, if used in isolation (i.e., without fair value pricing), a redemption fee of roughly $2.5 \%$ imposed on all fund transactions within a 90-day period would be necessary to preclude the exploitation of Asian-Pacific equity funds [Zitzewtiz (2003)].

\section{Transaction Limits}

Another barrier that could be used to reduce fund timing opportunities is to impose transaction limits on fund investors. The virtue of this solution is that it there are little explicit costs beyond that of monitoring the frequency of fund investors' transactions. However, transaction limits do not eliminate timing opportunities; it just reduces their frequency - arbitrageurs can still earn abnormal profits of up to $10 \%$ with as few as 3 round-trip transactions per year in Asian-Pacific equity funds [Zitzewitz (2003)]. Furthermore, to the extent that fund timers are able to rotate their transactions across a number of different funds, it may have little real impact on their activities. Furthermore, the implementation of transaction limits faces the same issues as redemption fees existing contracts and omnibus accounts. Finally, as with the cases of next-day pricing and redemption fees, transaction limits undermine one of the benefits of investing in mutual funds - liquidity. 


\section{A Comprehensive Solution to the Problem}

From the previous discussion, no single solution to the fund timing problem is both fully effective and costless. Each of the above solutions is subject to either practical limitations or significant costs. Fair value pricing is relatively costless compared to redemption fees, yet not completely effective. By contrast, redemption fees can be very effective, yet impose considerable costs.

The opposing nature of the trade-offs across these solutions suggests that some combination of the approaches might be optimal. For example, one could use fair value pricing to remove most of the predictability in NAV combined with a modest redemption fee to preclude the exploitation of any remaining predictability. This solution would be both effective and cost efficient. Market timing studies suggest that the round-trip profit opportunities from timing foreign equity funds seldom exceed 200 basis points. To the extent that staleness accounts for $75 \%$ of the profit opportunity, a fair value pricing methodology that corrects only for stale pricing would reduce the profit opportunity to 50 basis points. Thus a redemption fee of 50 basis points for trades within a 90 -day period would effectively preclude market timing and greatly limit if not eliminate other types of fund timing that attempt to exploit predictability that is unrelated to market volatility (i.e., weekend effect January effect, etc.).

Alternatively, one could use fair value pricing in conjunction with transaction limits. Recall that, in the most extreme cases arbitrageurs can earn abnormal profits of $10 \%$ from three round-trip transactions in fund shares. However, if a limit of three-roundtrip transactions per year were used in conjunction with fair value pricing, the arbitrageurs annual abnormal profit opportunity in these funds would be reduced to less than $2.5 \%$, an amount that may not be worth the arbitrageurs' nuisance costs.

These examples were used for illustrative purposes and are not intended to be suggestive of the optimal combination of these solutions nor their specific parameters - that will vary on a fund-by-fund basis. The important point is that, given the practical limitations of removing predictability and the cost of imposing barriers, the most effective and efficient solution involves a balanced and modest attack on each front. 


\section{References}

Adamati and Pfleiderer (1988), "A theory of intraday patterns: volume and price variability”, Review of Financial Studies, 1, 3-40.

Badrinath, Kale, and Noe (1995), "Of shepards, sheep, and the cross-autocorrelations in equity returns", Review of Financial Studies, 8, 401-430.

Barberis and Thaler (2003), "A survey of behavioral finance", Handbook of the Economics of Finance.

Bernard and Thomas (1990), "Evidence that stock prices do not fully reflect the implications of current earnings for future earnings", Journal of Accounting and Economics, 13, 305-340.

Bessembinder and Hertzel (1993), "Return autocorrelations around nontrading days", Review of Financial Studies, 6, 155-189.

Bhargava, Bose, and Dubofsky (1998), "Exploiting international stock market correlations with open-end international mutual funds", Journal of Business Finance, and Accounting, $25,765-773$.

Boudoukh, Richardson, Subrahmanyam, and Whitelaw (2002), "Stale prices and strategies for trading mutual funds", Financial Analyst Journal, July, 53-71.

Boudoukh, Richardson, and Whitelaw (1994), "A tale of three schools: insights on the autocorrelations of short-horizon stock returns", Review of Financial Studies, 7, 539-573.

Brennan, Jagadeesh, Swaminathan (1993), "Investment analysis and the adjustment of stock prices to common information", Review of Financial Studies, 6, 799-824.

Chalmers, Edelen, and Kadlec (2001), "On the perils of security pricing by financial intermediaries: the wildcard option in transacting mutual fund shares", Journal of Finance, 56, 2209-2236.

Chordia and Swaminathan (2000), "Trading volume and cross-autocorrelations in stock returns", Journal of Finance, 55, 913-935.

Conrad and Kaul (1988), “Time-varying expected returns”, Journal of Business, 61, 409425.

Cowles and Jones (1937) "Some A Posteriori Probabilities in Stock Market Action", Econometrica, 5, 280-294.

Fama (1991), "Efficient capital markets: II", Journal of Finance, 46, 1575-1618.

Fisher (1966) "Some new stock market indices", Journal of Business, 39, 191-225.

Foster, Olsen, Shevlin (1984), "Earnings releases, anomalies, and the behavior of security returns, Accounting Review, 59, 574-603. 
French (1980), "Stock returns and the weekend effect", Journal of Financial Economics, $8,55-70$.

Gibbons and Hess (1981), "Day of the week effect and asset returns", Journal of Business, 54, 579-596.

Goetzmann, Ivkovic, and Rouwenhorst (2001), "Day trading international mutual funds: evidence and policy solutions", Journal of Financial and Quantitative Analysis, 36, 287 309.

Goldman and Sosin (1979), "Information dissemination, market efficiency, and the frequency of transactions", Journal of Financial Economics, 7, 29-61.

Greene and Hodges (2002), "The dilution impact of daily fund flows on open-end mutual funds", Journal of Financial Economics, 65, 131-158.

Hasbrouck and Sofianos (1993), "The trades of market makers: An empirical analysis of NYSE specialists", Journal of Finance, 48, 1565-1593.

Hawawini (1980), "The intertemporal cross price behavior of common stocks: evidence and implications", Journal of Financial Research, 3, 153-167.

Jegadeesh and Timan (1993), "Returns to buying winners and selling losers: implications for stock market efficiciency", Journal of Finance 48, 65-91.

Kadlec and Patterson (1999), A transactions data analysis of nonsynchronous trading", Review of Financial Studies, 12, 609-630.

Kavajecz and Odders-White (2003), "Technical analysis and liquidity provision", forthcoming, Review of Financial Studies.

Keim (1989), "Trading patterns, bid-ask spreads, and estimated security returns", Journal of Financial Economics, 25, 75-98.

Lo and MacKinlay (1990), "An econometric analysis of nonsynchronous trading", Journal of Econometrica, 45, 181-211.

Reinganum (1981), "The anomalous behavior of small stocks in January: empirical tests for tax-loss selling effects", Journal of Financial Economics, 12, 89-104.

Rozeff and Kinney (1976), "Capital market seasonality: the case of stock returns", Journal of Financial Economics, 3, 379-402.

Zitzewitz (2003), "Who cares about shareholders? Arbitrage-proofing mutual funds", Journal of Law, Economics, and Organization, 19,245-280. 